\title{
Effects of Waterlogging Stress on the Physiological Characteristics and Secondary Metabolites of Herbaceous Peony (Paeonia lactiflora Pall.)
}

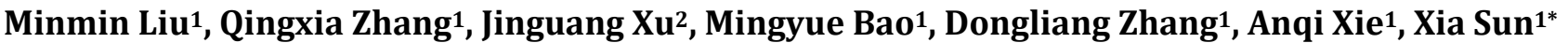 \\ ${ }^{1}$ State Key Laboratory of Crop Biology, College of Horticulture, Shandong Agricultural University, Taian, China \\ ${ }^{2}$ Shandong Academy of Forestry, Jinan, China \\ Email: guanshanghuayuan@163.com,2249865820@qq.com, *sunxia65@sina.com
}

How to cite this paper: Liu, M.M., Zhang, Q.X., Xu, J.G., Bao, M.Y., Zhang, D.L., Xie, A.Q. and Sun, X. (2021) Effects of Waterlogging Stress on the Physiological Characteristics and Secondary Metabolites of Herbaceous Peony (Paeonia lactiflora Pall.). American Journal of Plant Sciences, 12, 536-557. https://doi.org/10.4236/ajps.2021.124035

Received: March 5, 2021

Accepted: April 11, 2021

Published: April 14, 2021

Copyright $\odot 2021$ by author(s) and Scientific Research Publishing Inc. This work is licensed under the Creative Commons Attribution International License (CC BY 4.0).

http://creativecommons.org/licenses/by/4.0/

\begin{abstract}
Herbaceous peony is an ornamental plant with medicinal properties. Waterlogging can affect its yield and quality as it grows and matures. In this study, we subjected "Taohuafeixue", "Yangfeichuyu" and "Hongxiuqiu" herbaceous peony varieties to a simulated waterlogging stress treatment and investigated the effects of waterlogging on their physiological characteristics and the secondary metabolite contents in their leaves and roots. Short-term waterlogging caused the leaves to turn yellow or red and the roots to turn black. The stele and the cell wall of the endothelial cells thickened, and the cortical cells enlarged. Waterlogging did not significantly change plant height, leaf length, and leaf area; however, it significantly decreased the root-shoot ratio of "Yangfeichuyu" and "Hongxiuqiu" varieties. The activity of antioxidant enzymes and the content of osmotic regulators increased under waterlogging. After shortterm waterlogging stress treatment, the content of paeoniflorin and albiflorin increased in the roots of "Taohuafeixue" and "Yangfeichuyu", and the content of benzoylpaeoniflorin increased in the root of "Hongxiuqiu". The content of gallic acid and total flavonoids increased in the leaves of "Taohuafeixue" and "Yangfeichuyu". After the waterlogging, paeoniflorin and benzoylpaeoniflorin increased in the autumn root of "Hongxiuqiu". This study expands our knowledge about the medicinal properties of herbaceous peony and informs about its production and cultivation under waterlogged conditions.
\end{abstract}

\section{Keywords}

Waterlogging Stress, Secondary Metabolism, Herbaceous Peony, Antioxidant 
Enzymes, Osmotic Regulation, Microstructure

\section{Introduction}

Both biotic and abiotic stresses affect plant growth, and water stress is one of the most important abiotic stresses [1]. Waterlogging occurs in many parts of the world due to heavy rainfall and poor drainage systems [2]. In China, the main areas of herbaceous peony production are prone to waterlogging during the rainy season, especially in the south of China, where precipitation is concentrated and distributed unevenly during monsoons. Excessive and persistent water stress affects normal plant growth and development because it affects root respiration. Under water stress, soil aeration is poor and root respiration is limited; as a result, the absorption and transportation of inorganic matter and the transportation and distribution of photosynthetic products are affected, which not only changes the external morphology of plants, but also affects their metabolism, and subsequently the crop yield and quality [3] [4] [5] [6] [7]. The content of secondary metabolites is closely related to water stress in medicinal plants [8].

Under normal growth conditions, the production and removal of reactive oxygen species (ROS) is in a dynamic balance. Water stress increases ROS accumulation, which leads to protein degradation, lipid peroxidation, DNA and cell membrane damage, and impairs cell function [9] [10] [11]. However, ROS can be used as a signaling molecule to regulate plant growth, development, and adaptation to stress. Besides, it can stimulate plant antioxidant mechanisms to maintain the ROS keep balance. In addition, plants utilize cell osmotic regulation to accumulate organic matter, such as soluble sugars, soluble proteins, proline, and betaine and inorganic ions, such as $\mathrm{Ca}^{2+}$ and $\mathrm{Na}^{+}$. These molecules can increase the concentration of cell fluid, reduce the osmotic potential of cells, and enhance the ability of cells to absorb and retain water so that plants can adapt to the environment, maintaining normal growth and metabolism of cells and alleviating any damage [12]. Secondary metabolites in medicinal plants are also important for stress resistance, and they are susceptible to environmental conditions. They can play an important role in plant defense, viability, and the coordination of environmental interactions. Secondary metabolite content changes are also a hot topic in the research of medicinal plants [13] [14] [15].

Herbaceous peony (Paeonia lactiflora Pall.) is a perennial herb that belongs to the family Paeoniaceae. It is a popular traditional flower in China, widely used in gardens, and it is also an important medicinal plant [16] [17]. Herbaceous peony is suitable for higher and a dry planting ground. It is a deep-rooted plant and is suitable for deep sandy loam. It grows well in neutral or slightly acidic fertile soil and is not resistant to salty or alkaline soils. The roots of herbaceous peony are often used for medicinal purposes. The main active substances of herbaceous 
peony are paeoniflorin, benzoylpaeoniflorin, albiflorin, and oxypaeoniflorin, which are used for blood nourishment and cooling and reduction of swelling, inflammation, and tumors [18] [19]. All organs of herbaceous peony are rich in phenolic acids and flavonoids, which can treat and even prevent tumors and slow down aging [20] [21]. Shen et al. [22] found that the root content of paeoniflorin and albiflorin in herbaceous peony were season-dependent, and their optimal content for harvesting are observed in spring and autumn.

In recent years, research on the physiology of herbaceous peony has focused on cultivation techniques, the post-harvest physiology of cut flowers, regulation of the flowering period, storage, and preservation [24] [25] [26] [27]. Research on water stress in herbaceous peony has concentrated on the physiological mechanisms of response to drought stress [28] [29], and the medicinal research of herbaceous peony has mainly focused on its medicinal properties and pharmacological composition [30] [31]. There are no reports on the effect of waterlogging on secondary metabolite levels in herbaceous peony. The purpose of this study was to provide a reference for the cultivation of medicinal herbaceous peony under waterlogging conditions, to document the effect of waterlogging on the quality of herbaceous peony, and to provide a theoretical basis for the extraction of medicinal substances from herbaceous peony.

\section{Materials and Methods}

\subsection{Experimental Location and Materials}

The study was conducted from April to December, in 2019 at the Horticulture Test Station Herbaceous Peony Resources Nursery and the Horticulture Experiment Center of Shandong Agricultural University in Tai'an City $\left(35^{\circ} 38^{\prime} \mathrm{N}\right.$ $\left.116^{\circ} 02^{\prime} \mathrm{E}\right)$, Shandong Province, China. The study site is a temperate continental monsoon climate, with four distinct seasons, including hot and rainy seasons. The annual average temperature were $13^{\circ} \mathrm{C}$, and the average precipitation is 697 $\mathrm{mm}$.

In this experiment, three herbaceous peony varieties- "Taohuafeixue", "Yangfeichuyu", and "Hongxiuqiu" - with similar vegetative growth patterns and flowering periods were selected. The selected plants were healthy showed no signs of pest damage or disease. Each variety consisted of 40 trees.

\subsection{Experimental Design}

The pots were allocated to a randomized block design, including two water treatments-the control group (CK) and the waterlogged group (WL). There are 20 trees per group and 5 trees for morphological observation. Three-year-old herbaceous peony plants were potted in sandy loam (pot size: $30 \mathrm{~cm}$ high, $33 \mathrm{~cm}$ in diameter, $27 \mathrm{~cm}$ in diameter). The control treatment followed the conventional water management. The waterlogged group was treated with semi-flooding, and the water surface height should be kept at $1 / 2$ of the flower pot, watered at 8:00 am and 6:00 pm every day. The pots were covered with reed curtains to prevent 
water temperature changes in the basin. When $60 \%$ of the leaves showed symptoms of damage-by turning red or yellow-waterlogging was stopped, at the end of recovery, the discolored leaves were green. Preliminary experiments showed that when more than $60 \%$ of the leaves were damaged, it was difficult to restore normal growth after waterlogging was stopped. The restoration period ended when the leaves turned green. Pictures of the same locations and mature leaves and roots were taken at the beginning of the waterlogging treatment, the end of the damage period, and the end of the recovery period. The roots and leaves at the three stages were sampled, and taken back with ice box and stored in a refrigerator at $-80^{\circ} \mathrm{C}$ for the detection of physiological parameters and the content of secondary metabolites. We sampled the roots in autumn to detect the effects of waterlogging on secondary metabolites in October. Every indicator test was repeated three times and we reported the average value.

\subsection{Production and Observation of Paraffin Section of the Root}

A robust herbaceous peony root was selected to make paraffin sections following the method described by Chen [32] to production of paraffin section of the root. The root was rinsed with water and placed in a FAA fixed solution, taken out, and washed with the ethanol. The root was then dehydrated with ethanol, and immersed in a 1:1 mixture of ethanol and xylene, to achieve tissue transparency. The root was then embedded into paraffin wax, sectioned, and stained with saffron reagent. The excess staining reagent was removed with water, a neutral resin was added, and a coverslip was carefully placed over the specimen, which was placed on a glass slide. The slides were left to dry out with oven that the temperature is $30^{\circ} \mathrm{C}-40^{\circ} \mathrm{C}$, and images of the sections were taken with the $\mathrm{Mi}$ crograph system.

\subsection{Quantification of Physiological Indicators}

\subsubsection{Quantification of SOD, POD, and CAT Activities and MDA Content} Superoxide dismutase (SOD) activity was determined by photochemical reduction of nitrogen blue tetrazole (NBT), peroxidase (POD) was determined by the guaiacol method, catalase (CAT) was determined by UV absorption, malondialdehyde MDA was determined by the thiobarbituric acid method [33].

\subsubsection{Quantification of Osmotic Adjustment Substances}

Soluble sugar (SSC) was determined by anthrone colorimetry, soluble protein (SP) was determined by Coomassie Brilliant Blue method, proline (Pro) was determined by the sulfosalicylic acid method [33].

\subsection{Quantification of Secondary Metabolites}

\subsubsection{Quantification of Paeoniflorin, Benzoylpaeoniflorin, Albiflorin, and Gallic Acid}

Extraction method

The determination of paeoniflorin, benzoylpaeoniflorin, albiflorin, and gallic acid was performed using the method of $\mathrm{Li}$ [34]. A total of $0.1 \mathrm{~g}$ of the sample 
was put into a $25 \mathrm{~mL}$ volumetric flask $20 \mathrm{~mL}$ of $50 \%$ ethanol was added, soaked for $2 \mathrm{~h}$. Then ultrasonic treatment was conducted for $30 \mathrm{~min}$ at $26^{\circ} \mathrm{C}$. The sample was taken out and cooled; 50\% ethanol was added to dilute it and then the flask was well shaken. Finally the supernatant was then removed and passed through an organic membrane and put into a $2 \mathrm{~mL}$ sample bottle for testing.

Chromatographic conditions and standard

HPLC was performed using a vanusilmp c18 chromatographic column (100 $\mathrm{mm} \times 4.6 \mathrm{~mm}, 5 \mu \mathrm{m})$. The mobile phase was as follows: A $0.1 \%$ phosphoric acid aqueous solution $(\mathrm{pH}=2.7), \mathrm{B}$ acetonitrile; gradient elution: 0 - $5 \mathrm{~min}, 10 \%$ $15 \%$ B; 5 - $25 \min , 15 \%$ - 22\% B; 25 - $45 \min , 22 \%$ - 70\% B; 45 - $46 \min , 70 \%$ $80 \% \mathrm{~B}$; 46 - $48 \mathrm{~min}, 80 \% \mathrm{~B}$; volume flow rate: $0.8 \mathrm{~mL} \cdot \mathrm{min}^{-1}$; flow speed: 0.4 $\mathrm{mL} \cdot \mathrm{min}^{-1}$; detection wavelengths: $230 \mathrm{~nm}$ and $270 \mathrm{~nm}$; column temperature: $30^{\circ} \mathrm{C}$; and injection volume: $10 \mu \mathrm{L}$. The standard product was Solarbio.

\subsubsection{Quantification of Total Flavonoids \\ Drawing of the standard curve}

Accurately absorb of rutin standard solution $1 \mathrm{ml}, 2 \mathrm{ml}, 3 \mathrm{ml}, 4 \mathrm{ml}$ and $5 \mathrm{ml}$, and put it in $50 \mathrm{ml}$ volumetric flask respectively. Add absolute ethanol to a total volume of $15 \mathrm{~mL}$, add $1 \mathrm{ml}$ of aluminum nitrate solution and $1 \mathrm{~mL}$ of potassium acetate solution, shake well, add distilled water to the mark and shake for $1 \mathrm{~h}$, then use $30 \%$ ethanol solution as a control. Colorimetry at $420 \mathrm{~nm}$, and measure absorbance. Align the standard curve with the mass (mg) of $50 \mathrm{~mL}$ aloe vera as the abscissa and absorbance as the ordinate.

\section{Detection of content}

Total flavonoids were quantified following the method described by $\mathrm{Xu}$ [35]. We added $0.5 \mathrm{~g}$ of sample to absolute ethanol, allowed it to leach in an ultrasonic cleaner, and then filtered the leachate into a $25 \mathrm{~mL}$ volumetric flask for testing. The quantity of the test sample solution $(1.0 \mathrm{~mL})$ was accurately measured, and the measured sample was placed in a $50 \mathrm{~mL}$ volumetric flask. The absorbance was measured at $420 \mathrm{~nm}$ using a $30 \%$ ethanol solution as a standard to calculate the total flavonoid content.

\subsection{Statistical Analysis}

All the data in this study were analyzed and plotted using Microsoft Excel (Microsoft, Redmond, WA, USA) and SPSS statistics Version 19.0 (IBM Corporation, Armonk, NY, USA). One-way ANOVA was used to test the significance of each variable across the different treatments and herbaceous peony varieties, and the Duncan test was used for multiple comparisons.

\section{Results}

\subsection{Effect of Waterlogging on the Morphology of Herbaceous Peony}

\subsubsection{Waterlogging Treatment Date for Different Herbaceous Peony Species}

Waterlogging was started on the $29^{\text {th }}$ of April, when the vegetative growth had 
stopped and the plants began to enter the flower opening stage (Table 1). The symptoms of waterlogging treatment appeared after a different number of days for each variety: "Taohuafeixue" (12 d) > "Yangfeichuyu" (10 d) > "Hongxiuqiu" $(7 \mathrm{~d})$. The time from waterlogging relief to the end of recovery was as follows: "Yangfeichuyu" (9d) = "Hongxiuqiu" (9 d) > "Taohuafeixue" (6 d).

\subsubsection{Effects of Waterlogging Damage on the Morphological Indexes of Herbaceous Peony}

The leaves of WL were affected by waterlogging stress and the growth of CK leaves was normal (Figure 1). However, in the WL group, at the end of the waterlogging treatment the leaves showed different degrees of curling, and their color changed to yellow or red. The color change of "Yangfeichuyu" leaves was the most obvious. At end of the recovery period, the leaves of the three varieties showed no obvious curling and their color was similar to that of the CK.

At the beginning of the waterlogging the roots were healthy (Figure 2). When the waterlogging treatment finished, the roots of WL were black, and the most obvious symptoms were the "Taohuafeixue". From the waterlogging removal to the end of recovery the color of roots change was not obvious. The waterlogged herbaceous peony had thicker root stele and cell wall of the endothelial cells. Moreover, waterlogging increased the size of root xylem and cortical cells. Among the tested varieties, "Taohuafeixue" showed the least changes, while "Yangfeichuyu" showed an obvious enlargement of cells in the stele and cortical cells of lateral roots. The lateral root changes were more pronounced than the

Table 1. Date of waterlogging treatment for three herbaceous peony varieties, "Taohuafeixue", "Yangfeichuyu", and "Hongxiuqiu".

\begin{tabular}{cccc}
\hline \multirow{2}{*}{ Variety } & \multicolumn{3}{c}{ The date of waterlogging treatment } \\
\cline { 2 - 4 } & Waterlogging begin & Waterlogging relief & End of recovery \\
\hline "Taohuafeixue" & April 29 & May 11 & May 17 \\
"Yangfeichuyu" & April 29 & May 9 & May 18 \\
"Hongxiuqiu" & April 29 & May 6 & May 15 \\
\hline
\end{tabular}

Note: Waterlogging begin: at the end of vegetative growth, it entered the flowering stage, and the growth state was basically in the same stage; Waterlogging relief: when $60 \%$ of the leaves showed symptoms of damage-by turning red or yellow; End of recovery: when the leaves turned green.

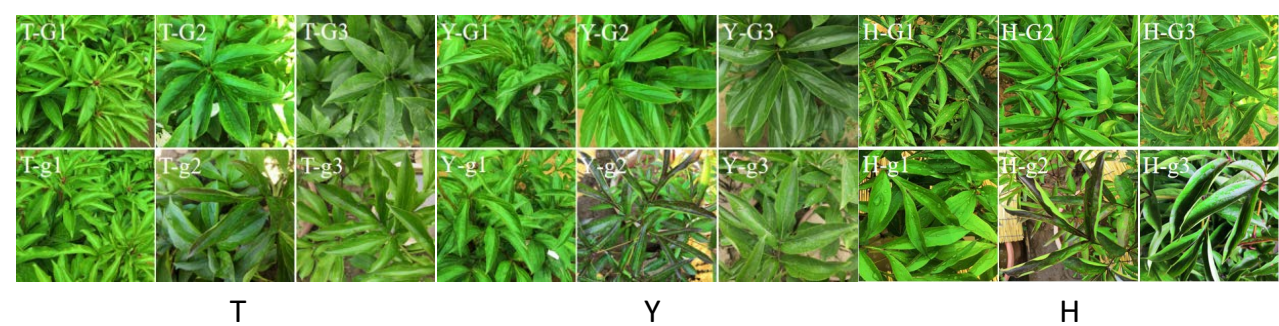

Figure 1. Effect of waterlogging treatment on the leaf morphology of tested herbaceous peony varieties. Note: T: "Taohuafeixue", Y: "Yangfeichuyu", H: "Hongxiuqiu”, the treatments were control $(\mathrm{G})$ and waterlogged $(\mathrm{g})$; the treatment stages were 1: initiation of waterlogging treatment, 2 : waterlogging relief, and 3: end of recovery. 

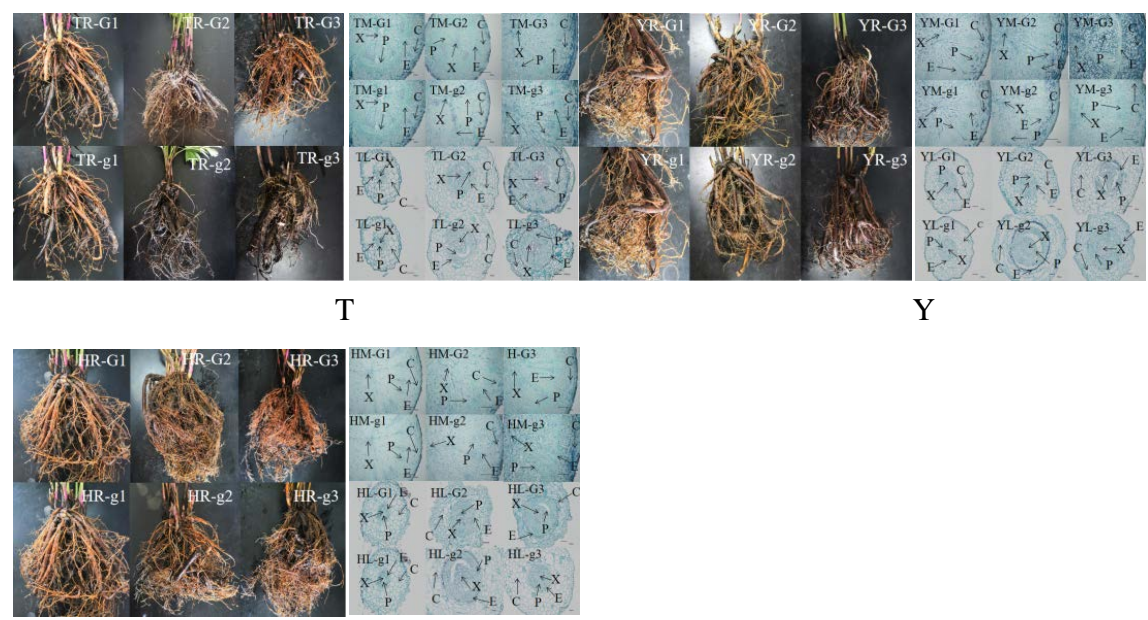

$\mathrm{H}$

Figure 2. Effects of waterlogging treatments on the root morphology and main and lateral root microstructures of tested herbaceous peony varieties. Note: T: "Taohuafeixue", Y: "Yangfeichuyu", H: "Hongxiuqiu". The treatments were control (G) and waterlogged (g); the treatment stages were 1: initiation of waterlogging treatment, 2: waterlogging relief, and 3: end of recovery. C: cortical cells, X: xylem, P: phloem, E: endothelial layer, R: root morphology, M: main root, L: lateral root.

main root changes. Although, at the end of recovery the stele and cortical cells of "Yangfeichuyu" were slightly restored, they were still different from those of $\mathrm{CK}$, and the stele and cortical cells of "Hongxiuqiu" recovered better.

\subsubsection{Effects of Waterlogging Damage on the Growth Indexes of Herbaceous Peony}

Waterlogging did not significantly affect the plant height, leaf length and leaf area of herbaceous peony $(\mathrm{P}>0.05$; Table 2$)$. At the waterlogging stress was relieved, the root-shoot ratios of "Yangfeichuyu" decreased significantly by $25.89 \%$ and "Hongxiuqiu" was 13.93\% $(\mathrm{P}<0.05)$ respectively. The root-shoot ratio of "Taohuafeixue" was lower than that of the CK, but not significantly. At the end of recovery, the difference between the root-shoot ratios of the WL and the CK of "Yangfeichuyu" was small, and the root-shoot ratios of the WL of "Taohuafeixue" and "Hongxiuqiu" were lower than that of the CK.

\subsection{Effect of Waterlogging on the Physiological Indicators of Herbaceous Peony}

\subsubsection{Changes in Antioxidant Enzyme Activity and MDA Content}

Waterlogging affected the activity of SOD in the leaves and roots of herbaceous peony; the SOD activity increased first and then decreased. The activity was the highest and higher than that of $\mathrm{CK}$ when waterlogging was stopped (Figure $3(\mathrm{~A})$, Figure $3(\mathrm{~B})$ ). The change of the SOD level was the most significant for "Taohuafeixue" ( $\mathrm{P}<0.05)$, with increases of $109.92 \%$ and $79.15 \%$ observed in leaves and roots, respectively. For the "Yangfeichuyu" variety, the SOD levels in leaves and roots increased by $53.93 \%$ and $48.98 \%(\mathrm{P}<0.05)$, respectively, and in the "Hongxiuqiu" variety these levels increased by $41.13 \%$ and $60.50 \%(\mathrm{P}<0.05)$ 
Table 2. Effects of waterlogging treatment on growth indexes of the tested herbaceous peony varieties "Taohuafeixue", "Yangfeichuyu", and "Hongxiuqiu".

\begin{tabular}{|c|c|c|c|c|c|c|}
\hline Variety & Processing period & Treatment group & Plant height $(\mathrm{cm})$ & Leaf length $(\mathrm{cm})$ & Leaf area $\left(\mathrm{cm}^{2}\right)$ & Root-shoot ratio \\
\hline \multirow{6}{*}{ "Taohuafeixue" } & \multirow{2}{*}{ Waterlogging begin } & CK & $60.00 \pm 1.53 a$ & $8.20 \pm 0.15 c$ & $20.93 \pm 0.92 \mathrm{a}$ & $2.43 \pm 0.17 \mathrm{a}$ \\
\hline & & WL & $59.67 \pm 4.70 \mathrm{a}$ & $8.50 \pm 0.15 c$ & $21.22 \pm 0.63 a$ & $2.32 \pm 0.03 a$ \\
\hline & \multirow{2}{*}{ Waterlogging relief } & CK & $60.00 \pm 0.58 \mathrm{a}$ & $8.87 \pm 0.03 b$ & $22.31 \pm 0.99 a$ & $1.81 \pm 0.02 \mathrm{~b}$ \\
\hline & & WL & $59.67 \pm 1.20 \mathrm{a}$ & $8.67 \pm 0.18 b$ & $22.15 \pm 0.93 a$ & $1.68 \pm 0.03 b c$ \\
\hline & \multirow{2}{*}{ End of recovery } & CK & $64.33 \pm 0.88 \mathrm{a}$ & $9.50 \pm 0.06 \mathrm{a}$ & $22.73 \pm 0.48 \mathrm{a}$ & $1.47 \pm 0.03 c$ \\
\hline & & WL & $64.00 \pm 2.30 \mathrm{a}$ & $9.30 \pm 0.1 \mathrm{a}$ & $22.57 \pm 0.39 a$ & $1.24 \pm 0.04 \mathrm{~d}$ \\
\hline \multirow{6}{*}{ "Yangfeichuyu" } & \multirow{2}{*}{ Waterlogging begin } & CK & $69.00 \pm 1.15 \mathrm{a}$ & $9.23 \pm 0.15 \mathrm{~d}$ & $27.41 \pm 0.70 \mathrm{~b}$ & $2.22 \pm 0.06 \mathrm{a}$ \\
\hline & & WL & $69.33 \pm 0.33 a$ & $9.13 \pm 0.12 \mathrm{~d}$ & $27.98 \pm 0.57 b$ & $2.11 \pm 0.07 \mathrm{c}$ \\
\hline & \multirow{2}{*}{ Waterlogging relief } & $\mathrm{CK}$ & $75.00 \pm 3.51 \mathrm{a}$ & $10.30 \pm 0.10 c$ & $31.8 \pm 1.27 \mathrm{a}$ & $1.97 \pm 0.05 b$ \\
\hline & & WL & $70.33 \pm 2.33 \mathrm{a}$ & $10.57 \pm 0.23 c$ & $32.22 \pm 0.59 \mathrm{a}$ & $1.46 \pm 0.04 c$ \\
\hline & \multirow{2}{*}{ End of recovery } & CK & $78.00 \pm 3.00 \mathrm{a}$ & $11.03 \pm 0.03 b$ & $32.53 \pm 0.30 \mathrm{a}$ & $2.06 \pm 0.04 \mathrm{ab}$ \\
\hline & & WL & $73.00 \pm 5.77 \mathrm{a}$ & $11.47 \pm 0.08 \mathrm{a}$ & $32.3 \pm 0.53 a$ & $2.16 \pm 0.09 \mathrm{ab}$ \\
\hline \multirow{6}{*}{ "Hongxiuqiu" } & \multirow{2}{*}{ Waterlogging begin } & CK & $56.00 \pm 1.53 a$ & $9.27 \pm 0.52 b$ & $20.01 \pm 0.39 b$ & $2.26 \pm 0.04 \mathrm{~b}$ \\
\hline & & WL & $57.00 \pm 0.58 \mathrm{a}$ & $10.03 \pm 0.43 \mathrm{ab}$ & $21.83 \pm 0.23 \mathrm{ab}$ & $2.27 \pm 0.03 \mathrm{~b}$ \\
\hline & \multirow{2}{*}{ Waterlogging relief } & CK & $55.67 \pm 0.67 \mathrm{a}$ & $10.83 \pm 0.17 \mathrm{a}$ & $22.79 \pm 1.35 \mathrm{a}$ & $2.44 \pm 0.05 a$ \\
\hline & & WL & $57.33 \pm 0.33 a$ & $9.23 \pm 0.63 b$ & $22.14 \pm 0.3 \mathrm{ab}$ & $2.1 \pm 0.03 \mathrm{bc}$ \\
\hline & \multirow{2}{*}{ End of recovery } & CK & $57.00 \pm 0.58 \mathrm{a}$ & $9.83 \pm 0.58 \mathrm{ab}$ & $22.17 \pm 0.76 \mathrm{ab}$ & $2.04 \pm 0.06 c$ \\
\hline & & WL & $56.67 \pm 0.88 \mathrm{a}$ & $10.8 \pm 0.05 a$ & $21.96 \pm 0.36 \mathrm{ab}$ & $1.62 \pm 0.09 \mathrm{~d}$ \\
\hline
\end{tabular}

Note: Means that do not share a letter are different at $\mathrm{P}<0.05$. Data are mean \pm standard error.
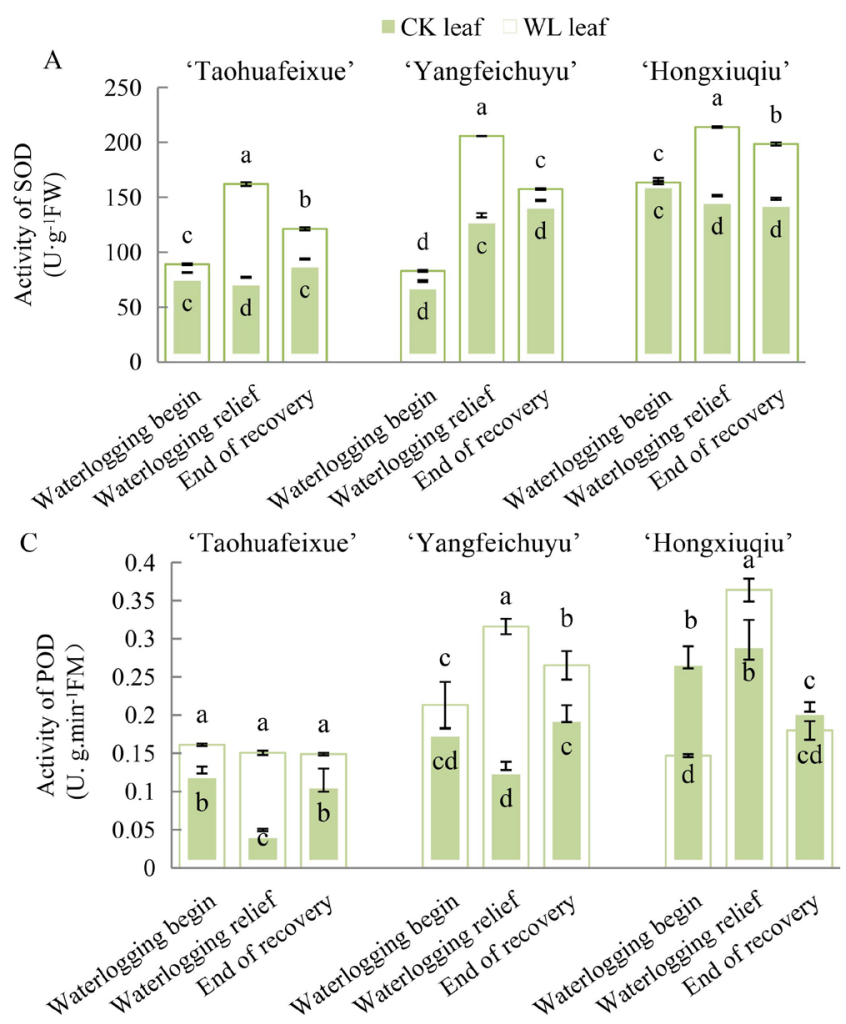
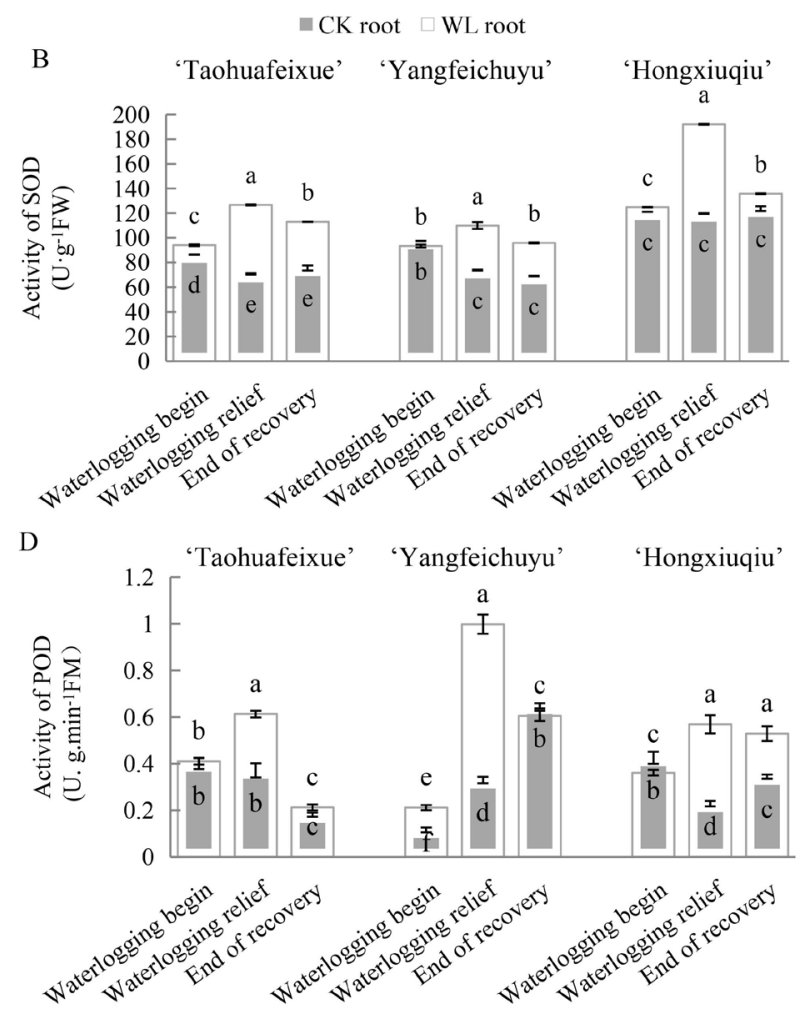

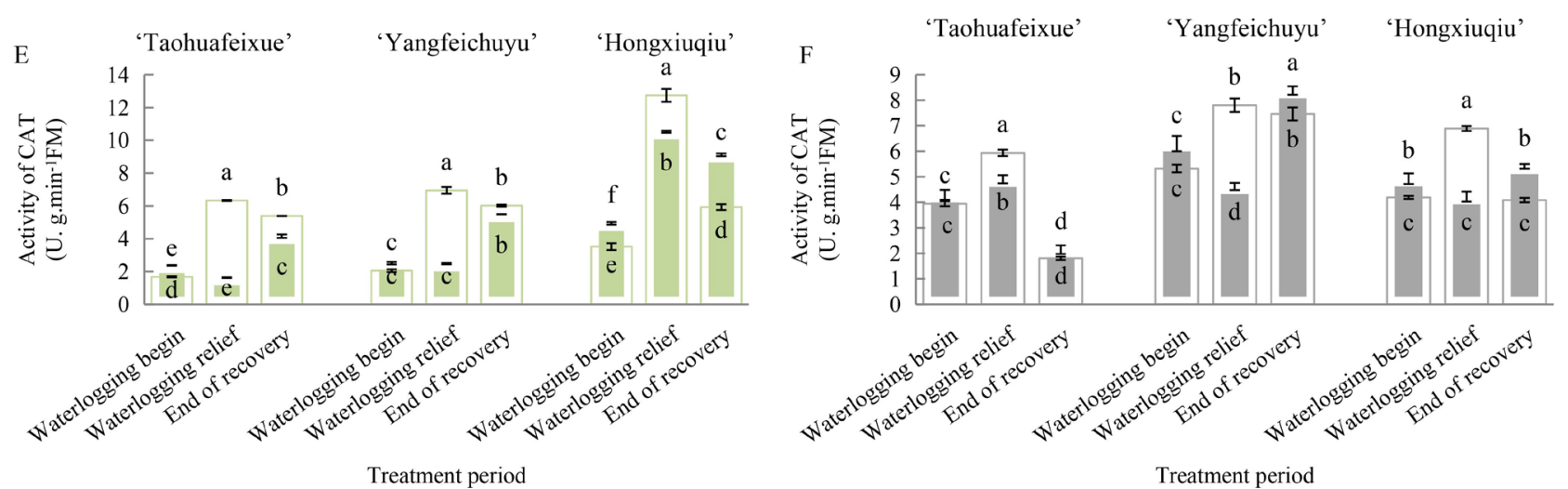

Figure 3. Effects of waterlogging treatment on the activities of SOD ((A)-(B)), POD ((C)-(D)), CAT ((E)-(F)) in the leaves and roots of herbaceous peony varieties "Taohuafeixue", "Yangfeichuyu", and "Hongxiuqiu". Note: Green represents the change of antioxidant enzyme activity in leaves; Grey represents the change of antioxidant enzyme activity in root system. Means that do not share a letter are different at $\mathrm{P}<0.05$. Data are mean \pm standard error.

in leaves and roots, respectively. After waterlogging ceased, SOD activity decreased, but was still higher than that in CK plants.

The change in POD activity under waterlogging showed a trend of first rising and then falling; the maximum value appeared when waterlogging stopped (Figure 3(C), Figure 3(D)). When the waterlogging was stopped, the biggest change in POD activity was observed in leaves of "Yangfeichuyu", at $146.15 \%$ (P $<0.05$ ), and the smallest change was observed in "Hongxiuqiu". In thesssss roots, the largest change in POD activity was observed in "Yangfeichuyu", with an increase of 203.03\%, and in "Taohuafeixue" and "Hongxiuqiu" the POD activity increased by $65.23 \%$ and $149.56 \%(\mathrm{P}<0.05)$, respectively. Both foliar and root POD activities were close to that of $\mathrm{CK}$ by the end of recovery.

Waterlogging increased the activity of CAT in herbaceous peony, with greater changes observed in the leaves compared to those in the roots (Figure 3(E), Figure $3(\mathrm{~F})$ ). When waterlogging was stopped, the CAT activities of the leaves of "Taohuafeixue", "Yangfeichuyu", and "Hongxiuqiu" increased by $288.34 \%$, $180.24 \%$, and $21.10 \%(\mathrm{P}<0.05)$, respectively compared with that of CK. In the roots, the CAT activities increased by $21.22 \%, 68.83 \%$, and $63.27 \%(\mathrm{P}<0.05)$, for "Taohuafeixue", "Yangfeichuyu", and "Hongxiuqiu", respectively. After the waterlogging was ceased, the CAT activities gradually decreased to values close to that of CK.

The MDA content is an index to measure the degree of injury of plant cell membranes under stress. At the beginning of waterlogging the difference between CK and WL was not obvious (Figure 4). When waterlogging was relieved, the content of MDA in "Taohuafeixue" and "Hongxiuqiu" leaves was slightly different from CK, and "Yangfeichuyu" was significantly lower than that of the CK. In the roots, however, the MDA content of "Hongxiuqiu" increased by about $239.84 \%$, compared to that in the CK $(\mathrm{P}<0.05)$. At the end of recovery, the MDA content of the WL was lower than that of the $\mathrm{CK}$ in both the leaves and roots of all three varieties. 


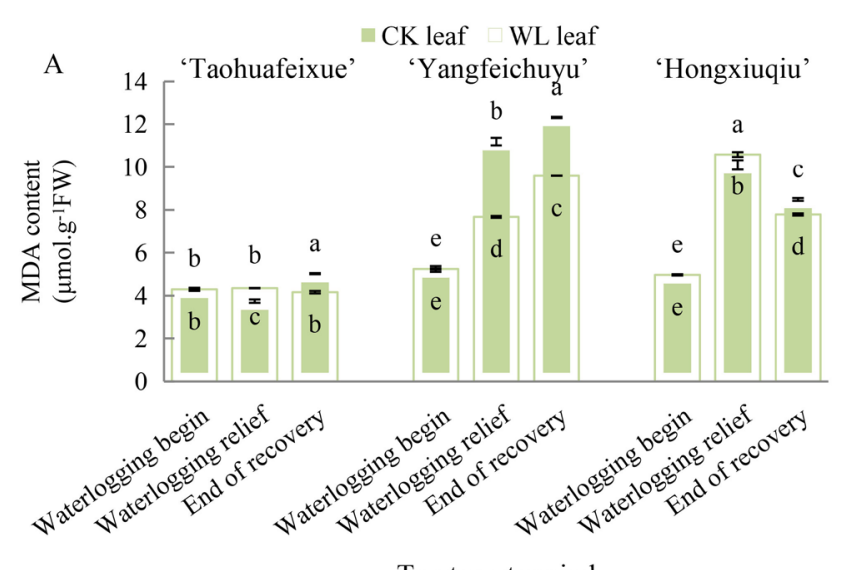

Treatment period

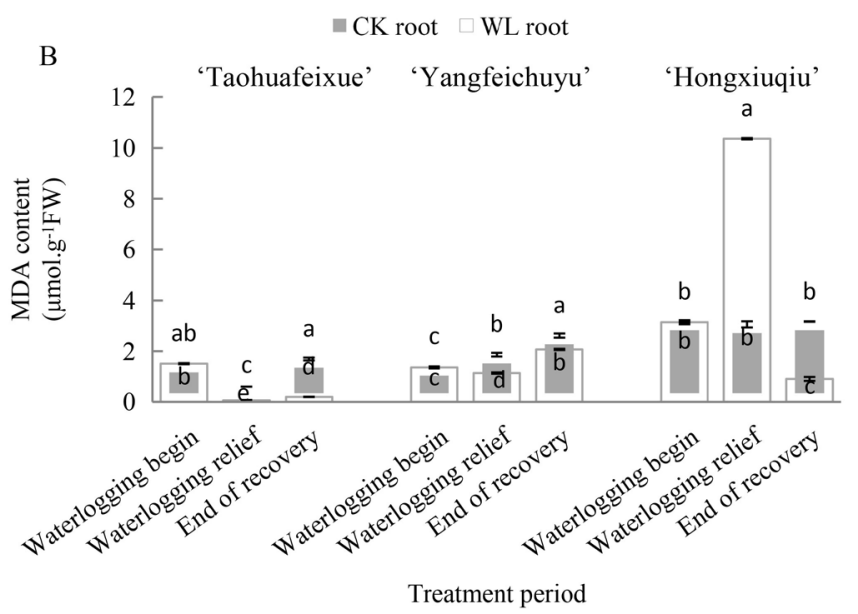

Figure 4. Effects of waterlogging treatment on the content of MDA in the leaves (A) and roots (B) of three herbaceous peony varieties "Taohuafeixue", "Yangfeichuyu", and "Hongxiuqiu". Note: Green represents the change of MDA content in leaves; Grey represents the change of MDA content in root system Means that do not share a letter are different at $\mathrm{P}<0.05$. Data are mean \pm standard error.

\subsubsection{Changes in Osmotic Adjustment Substances}

When the waterlogging was stopped, there was no significant effect on the content of SP in "Taohuafeixue". The content of SP in "Yangfeichuyu" increased first and then decreased, and it was close to that in the CK by the end of recovery. The content of SP in "Hongxiuqiu" leaves increased by $54.25 \%(\mathrm{P}<0.05)$, and, in the roots of "Hongxiuqiu" the SP levels increased by $18.8 \%(\mathrm{P}<0.05)$. During recovery, the leaf SP levels increased further (Figure 5(A), Figure 5(B)). This may have been due to the restoration of leaf color, but it still indicates the necessity of the plant to increase the content of SP to maintain the SP concentration within the cells and thus enable its normal growth. The content of SP in the root was close to CK.

Waterlogging had a significant effect on the SSC, by first increasing and then decreasing (Figure 5(C), Figure 5(D)). The increase of SSC was the most significant in the leaves of "Taohuafeixue" $(\mathrm{P}<0.05)$ and was followed by increases of SSC in the leaves of "Yangfeichuyu" and "Hongxiuqiu". At the end of recovery, the SSC in leaves of "Yangfeichuyu" significantly decreased $(\mathrm{P}<0.05)$, while that in the leaves of "Taohuafeixue" and "Hongxiuqiu" was still higher than that in the CK. When waterlogging was stopped, the increase in root SSC was the most significant in "Yangfeichuyu" $(\mathrm{P}<0.05)$, followed by those in "Hongxiuqiu" and "Taohuafeixue". At the end of recovery, root SSC has different trends in different varieties

When waterlogging was ceased, the Pro content in the leaves and roots were significantly higher than those prior to waterlogging; it decreased gradually after waterlogging relief (Figure 5(E), Figure 5(F)). The Pro content in the leaves of "Taohuafeixue", "Yangfeichuyu" and "Hongxiuqiu" increased by $164.88 \%$, $106.08 \%$, and $129.51 \%(\mathrm{P}<0.05)$, respectively, while those in the roots increased by $61.93 \%, 72.99 \%$, and $129.51 \%(\mathrm{P}<0.05)$, respectively. 

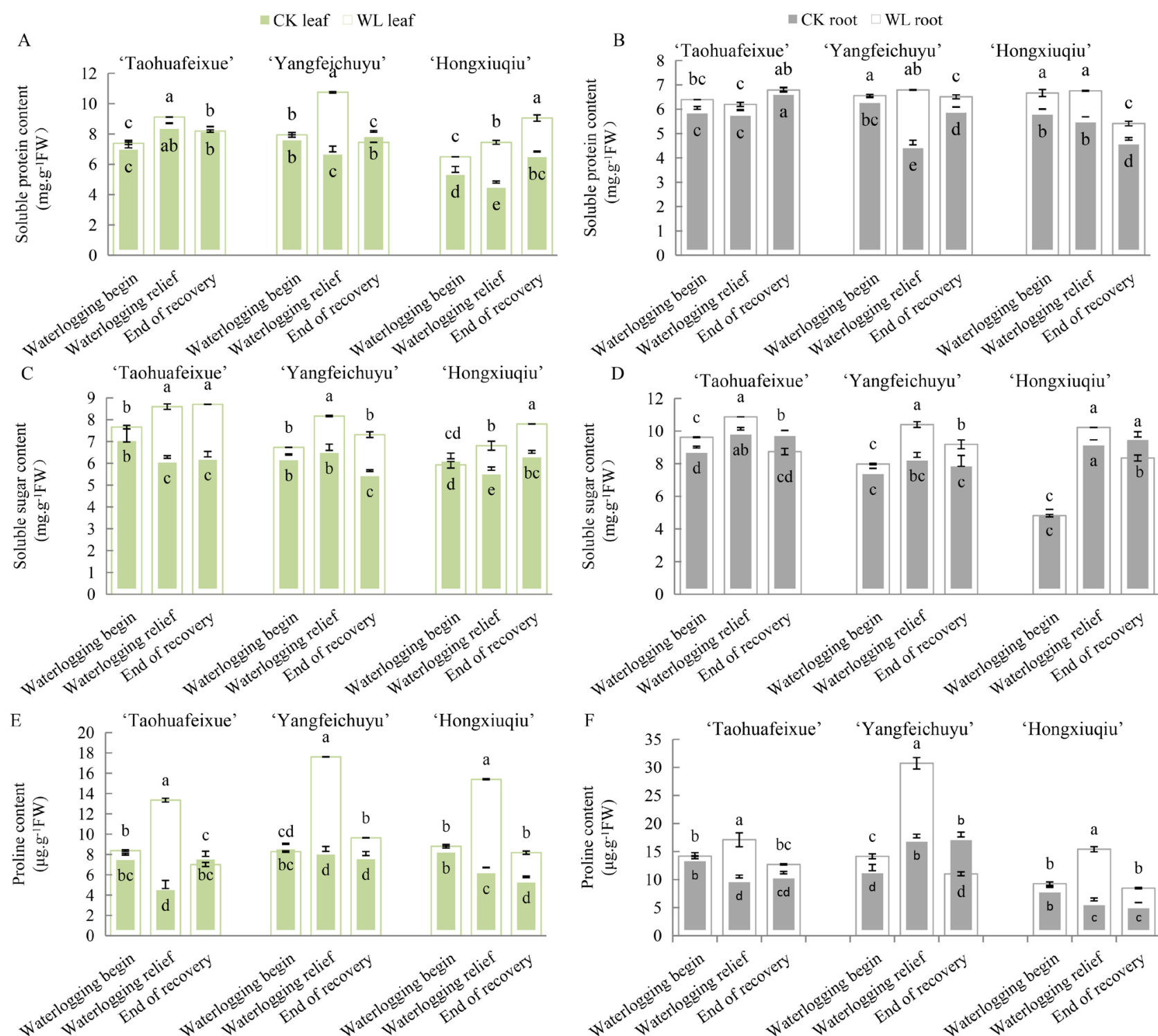

Treatment period

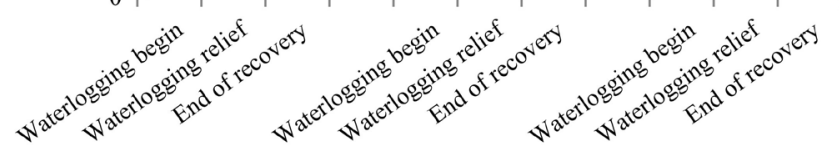

Treatment period

Figure 5. Effects of waterlogging treatment on the content of soluble protein (A-B), soluble sugar (C-D), and proline (E-F) of three herbaceous peony varieties "Taohuafeixue", "Yangfeichuyu", and "Hongxiuqiu". Note: Green represents the change of osmotic adjustment substances content in leaves; Grey represents the change of osmotic adjustment substances content in root system Means that do not share a letter are different at $\mathrm{P}<0.05$. Data are mean \pm standard error.

\subsection{Changes in Secondary Metabolite Content}

When waterlogging was stopped, the content of paeoniflorin in the roots significantly increased in "Taohuafeixue" and "Yangfeichuyu" $(\mathrm{P}<0.05)$ and decreased in "Hongxiuqiu" $(\mathrm{P}<0.05)$. After waterlogging was stopped, the content of paeoniflorin in "Taohuafeixue" was still higher than that in the $\mathrm{CK}$, while in "Yangfeichuyu" and "Hongxiuqiu" it was lower than that in the CK $(\mathrm{P}<0.05)$. Waterlogging increased the content of paeoniflorin in the leaves of "Yangfeichuyu" and "Hongxiuqiu". At the end of recovery, the content of paeoniflorin in "Hongxiuqiu" continued to increase, although it decreased significantly $(\mathrm{P}<$ 
0.05) in "Taohuafeixue". The downward trend of the paeoniflorin content in "Taohuafeixue" may indicate that waterlogging may affect the recovery of the paeoniflorin content in this variety due to serious damage caused by waterlogging over a long time (Figure 6(A-1)). In autumn, the content of paeoniflorin in roots was lower than that observed for plants under waterlogging treatment. The content of paeoniflorin in the roots of "Taohuafeixue" and "Yangfeichuyu" decreased significantly compared to that in the CK $(\mathrm{P}<0.05)$, while that in the roots of "Hongxiuqiu" increased (Figure 6(A-2)).

When waterlogging was stopped, the content of benzoylpaeoniflorin in the root was not significantly different between "Taohuafeixue" and the CK (P > 0.05). The benzoylpaeoniflorin content of "Yangfeichuyu" decreased by $39.43 \%$, while that of "Hongxiuqiu" increased by $134.95 \%(\mathrm{P}<0.05)$. At the end of recovery, the decrease in benzoylpaeoniflorin in "Hongxiuqiu" was less than that in the CK, which may be due to its weak waterlogging tolerance and the serious damage that it underwent. The reduced accumulation of benzoylpaeoniflorin after waterlogging was stopped resulted in a rapid decrease in benzoylpaeoniflorin levels. The difference between other varieties and CK was small. In the leaves of "Taohuafeixue" the benzoylpaeoniflorin levels decreased significantly $(\mathrm{P}<0.05)$; the benzoylpaeoniflorin content of "Yangfeichuyu" decreased by $19.79 \%$, while that of "Hongxiuqiu" increased by $12.83 \%(\mathrm{P}<0.05)$. At the end of recovery,

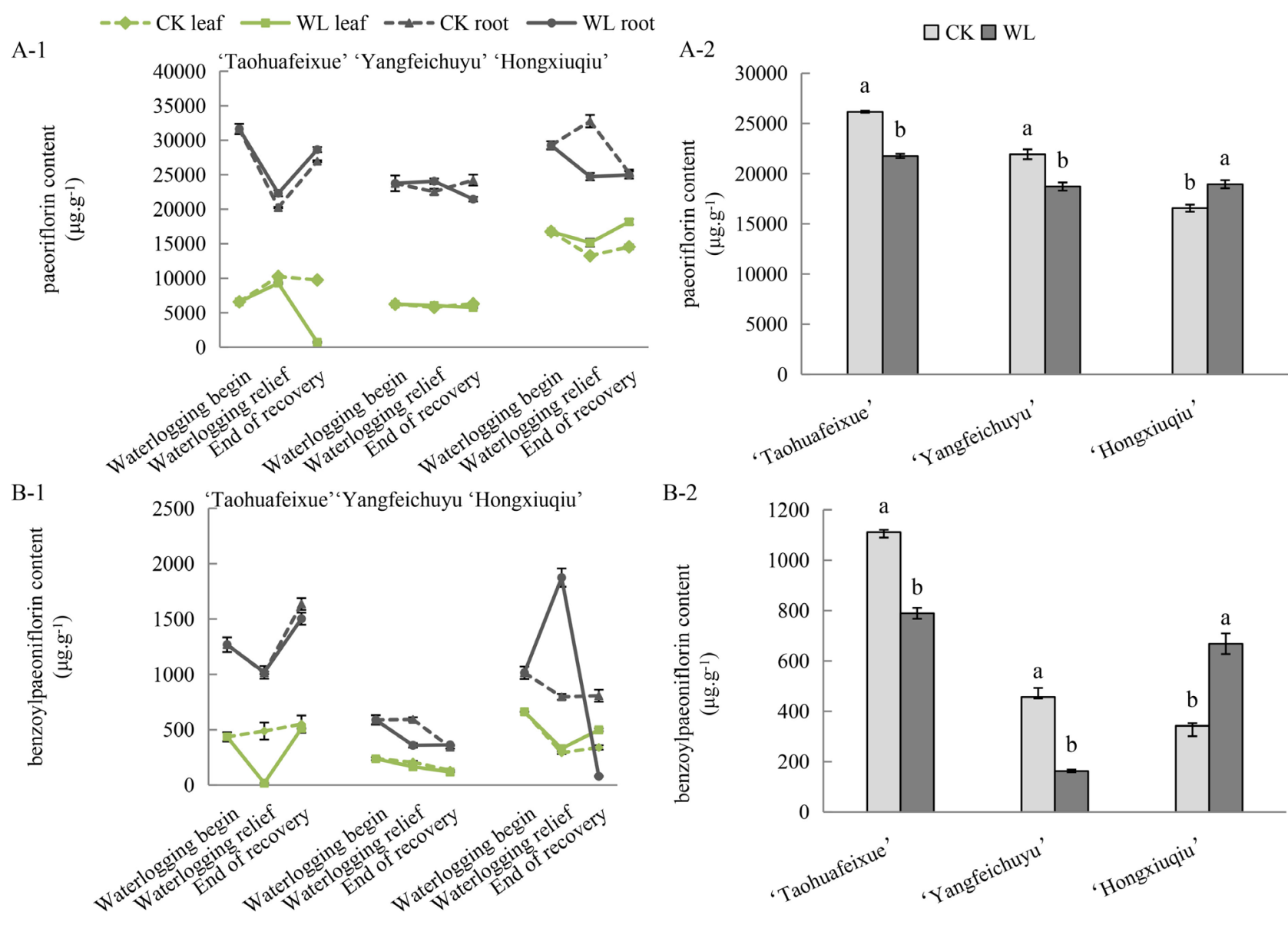



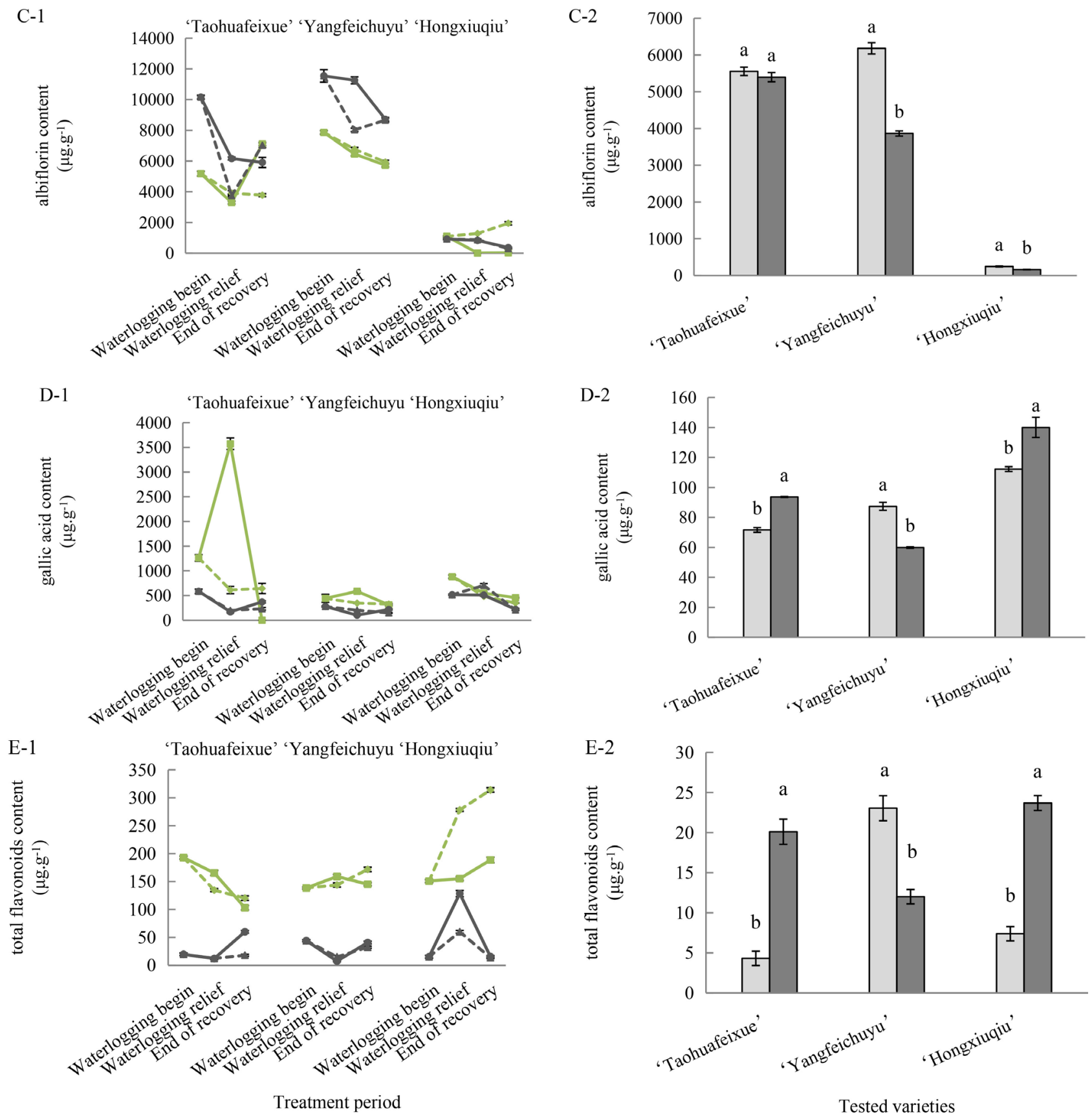

Figure 6. Effects of waterlogging treatment on the content of paeoniflorin (A), benzoylpaeoniflorin (B), albiflorin (C), gallic acid (D), and total flavonoids (E) in three herbaceous peony varieties "Taohuafeixue", "Yangfeichuyu", and "Hongxiuqiu". Note: 1: changes in secondary metabolites of leaves and roots of varieties under waterlogging, 2: changes in secondary metabolites of roots in autumn. Means that do not share a letter are different at $\mathrm{P}<0.05$. Data are mean \pm standard error.

"Hongxiuqiu" had a higher benzoylpaeoniflorin content than that of the CK, and the other two varieties had similar benzoylpaeoniflorin content, which were closer to that of the CK (Figure 6(B-1)). In autumn, the content of benzoylpaeoniflorin in the roots was lower than that in spring.The benzoylpaeoniflorin content of "Taohuafeixue" and "Yangfeichuyu" roots decreased by $29.01 \%$ and 64.27\%, respectively, and that of "Hongxiuqiu" increased by $95.3 \%(\mathrm{P}<0.05)$ 
(Figure 6(B-2)).

When waterlogging was stopped, the content of albiflorin in the roots of "Taohuafeixue" and "Yangfeichuyu" increased significantly $(\mathrm{P}<0.05)$, while that in the roots of "Hongxiuqiu" did not change significantly $(\mathrm{P}>0.05)$. At the end of recovery, the "Taohuafeixue" albiflorin content was significantly higher than that of the $\mathrm{CK}$, and, in the other two varieties, the albiflorin content tended to be closer to that in the CK. Waterlogging significantly reduced the content of albiflorin in leaves of "Taohuafeixue" and "Hongxiuqiu", but not in the leaves of "Yangfeichuyu" ( $P>0.05)$. At the end of recovery, the albiflorin content of "Taohuafeixue" increased significantly $(\mathrm{P}<0.05)$. However, the difference in the albiflorin content of "Hongxiuqiu" at the end of recovery was smaller than that at the end of waterlogging (Figure 6(C-1)). The content of albiflorin in the roots of "Yangfeichuyu" and "Hongxiuqiu" decreased by $37.47 \%$ and $34.08 \%$, respectively $(\mathrm{P}<0.05)$, and this change was not significant for "Taohuafeixue" $(\mathrm{P}>$ 0.05) (Figure 6(C-2)).

The foliar gallic acid content was significantly affected by waterlogging $(\mathrm{P}<$ 0.05), and the order of the content of foliar gallic acid in the three varieties was as follows: "Taohuafeixue" > "Yangfeichuyu" > "Hongxiuqiu". At the end of the recovery period, the content of gallic acid in the leaves of "Taohuafeixue" decreased to zero, which may have been due to its increase under the waterlogging treatment and the serious damage caused by waterlogging over a long time. However, the foliar gallic acid content in "Yangfeichuyu" and "Hongxiuqiu" were close to that in the CK. When waterlogging was stopped, there was no significant difference in the root gallic acid content of "Taohuafeixue" $(\mathrm{P}>0.05)$; however, there was a significant downward trend in the root gallic acid content of "Yangfeichuyu" and "Hongxiuqiu" $(\mathrm{P}<0.05)$. At the end of recovery, the gallic acid content was not different from that of the CK (Figure 6(D-1)). The content of gallic acid in the roots of "Taohuafeixue" and "Hongxiuqiu" in autumn were higher than that in the roots of the $\mathrm{CK}$; the content of gallic acid in the roots of "Yangfeichuyu" was lower than that in spring (Figure 6(D-2)).

Waterlogging significantly increased the content of total flavonoids in the leaves of "Taohuafeixue" and "Yangfeichuyu" $(\mathrm{P}<0.05)$, but the total flavonoid content decreased gradually upon recovery. During the normal growth period of "Hongxiuqiu", the total flavonoid content in the leaves increased, and it decreased under waterlogging. At the end of recovery, the total flavonoid content was significantly lower than that in the $\mathrm{CK}(\mathrm{P}<0.05)$. When waterlogging was stopped, the content of total flavonoids in the roots of "Hongxiuqiu" increased significantly $(\mathrm{P}<0.05)$, decreased in "Taohuafeixue", "Yangfeichuyu" $(\mathrm{P}>0.05)$. However, the flavonoid content in the WL roots of "Taohuafeixue" was higher than that in the roots of $\mathrm{CK}$ and was not significantly different from those of the CK and "Yangfeichuyu" and "Hongxiuqiu" (Figure 6(E-1)). The content of total flavonoids in the roots of the tested varieties in autumn was significantly lower than those in the plants under waterlogging treatment $(P<0.05)$. In the early waterlogging treatment, the root content of total flavonoids increased in "Tao- 
huafeixue" and "Hongxiuqiu" and decreased in "Yangfeichuyu" (Figure 6(E-2)).

\section{Discussion}

Waterlogging stress on herbaceous peony affects not only plant morphology but also plant physiology and metabolism [36]. In this study, the time of waterlogging relief and the end of recovery varied between varieties. "Taohuafeixue" was treated for the longest time and have the best water resistance. Waterlogging damage had little effect on the growth indexes of herbaceous peony. The waterlogging primarily affects the growth of the root and has little effect on other growth parameters. It appears that the herbaceous peony has strong adaptability of the species. In this study we measured both physiological parameters and secondary metabolite content to determine the effect of waterlogging on herbaceous peony.

Waterlogging damage leads to anoxia of plant roots, which is not conducive to the transport of substances and thus directly reflects in plant morphology, such as leaf discoloration, wilting or abscission, and changes in root microstructure [37] [38] [39]. We found that under waterlogged conditions, the leaves of tested herbaceous peony varieties turned red or yellow, and can recovery on its own. The roots turned black. Due to the excessive water content, toxic substances were produced in the root, which can lead to excessive accumulation of reducing substances, such as ferrous oxide [40]. The root was poisoned and blackened, and the color change of "Taohuafeixue" was the most obvious and was related to the duration of waterlogging. The waterlogging treatment increased the sizes of the stele, xylem, and cortical cells-and these results are consistent with Qu et al. [41]. These changes are associated with the water-stress coping mechanism, since they improve the absorption and transportation capacities of the root [32] [42].

ROS is an essential metabolite of aerobic metabolism for all aerobic organisms. In plants, it plays a role in the growth, development, differentiation, metabolism, and transportation of substances; defense responses; programmed cell death, and responses to biotic and abiotic stresses [43]. Waterlogging leads to ROS accumulation and intensifies membrane peroxidation and production of MDA [44]. The activities of SOD, POD, and CAT in the tested plants were detected in this experiment, and the activities of these enzymes were higher than those in the CK when waterlogging was stopped, consistent with previous studies [45] [46]. At the end of recovery, there was a different degree of decline compared with waterlogging relief, but different from $\mathrm{CK}$ in all three varieties. It shows that different varieties have different recovery ability. The increase in the MDA content was the largest in the root of "Hongxiuqiu" indicating that the waterlogging resistance of this variety was weakest and that the defense effect of the antioxidant enzyme system in its root was not obvious, resulting in the enhancement of membrane lipid peroxidation and serious injury. In contrast, "Taohuafeixue" and "Yangfeichuyu" had a strong waterlogging resistance, as the waterlogging in these varieties reduced the production of ROS, subsequently re- 
ducing the production of MDA and maintaining normal growth.

When plants are under stress, plant cells accumulate proteins that reduce their osmotic potential and increase cell ability to absorb water and maintain normal growth and metabolism [47]. Our results showed that waterlogging increased plant levels of SSC, SP, and Pro. The increases in SSC and SP differed between plant organs (leaf $>$ root) because it is related to the acceleration of leaf senescence and abscission under waterlogged conditions. After waterlogging is stopped, the content of SSC in the leaves is still increasing, and the macromolecular substances accumulated in plants are still being degraded, which leads to an increase in the SSC content [48]. The SSC and SP in the root gradually recovered in the present study. Proline also has antioxidant properties, which can promote cell stability by maintainingthe redox balance and reducing lipid peroxidation. The content of Pro increased with waterlogging and decreased gradually after waterlogging was relieved, which was consistent with the findings of Luo et al. [49]. It is showed that the herbaceous peony had a good osmotic regulation mechanism.

Secondary metabolites are the bioactive components of medicinal plants, which determine plant pharmacological properties and medicinal quality [50]. The synthesis and accumulation of secondary metabolites are not only regulated by related genes, but are also affected by environmental conditions [51] [52] [53]. Water is an important factor affecting the yield and quality of medicinal plants [54] [55]. A previous study showed that after drought stress, the content of saponins in the rhizomes of Paris polyphylla Smith var. increased, and the content of foliar saponins was higher than that in the stems [56]. Increased levels of polysaccharides and saponins in the root of Astragalus membranaceus were detected under mild drought stress [57]. Under sufficient water supply, the total phenolic content in eggplant leaves was lower than that under water and drought treatments [58]. The medicinal plant Balangu (Lallemantia sp.) was able to tolerate a certain degree of drought stress, and an increase in drought stress led to an increase in the production of secondary metabolites (e.g. phenolic compounds); furthermore, the production of secondary metabolites in Balangu could be regulated by adjusting the irrigation rate [59]. It is possible that changing one environmental factor could affect the content of several secondary metabolites and that the synthesis of one kind of secondary metabolite may be affected by many environmental factors.

Paeoniflorin, benzoylpaeoniflorin, and albiflorin are collectively measured as total paeoniflorin. These compounds are the active ingredients of herbaceous peony, with antiinflammatory, antioxidant, and anti-viral properties. Paeoniflorin mainly acts on the nervous, vascular, and endocrine systems. It has antidepressant, antioxidant, antitumor, and other properties [60] [61] [62]. This study showed that the content of paeoniflorin in "Taohuafeixue" and "Yangfeichuyu" roots increased with waterlogging, while that in "Hongxiuqiu" decreased significantly with waterlogging. The short-term waterlogging treatment was not conducive to the accumulation of paeoniflorin in the roots of "Taohuafeixue" and 
"Yangfeichuyu" in autumn, while the content of paeoniflorin in the roots of "Hongxiuqiu" increased significantly. The increase of paeoniflorin content in roots was not conducive to the accumulation in autumn. Benzoylpaeoniflorin can improve myocardial ischemia, hypoxia, depression, and bind oxygen free radicals. Waterlogging decreased the total benzoylpaeoniflorin content in "Taohuafeixue" and "Yangfeichuyu" leaves and roots but increased the content in "Hongxiuqiu", and the root increased more than leaf. Our results showed that waterlogging was sensitive to the synthesis of benzoylpaeoniflorin in the root of "Hongxiuqiu", and the increase in the benzoylpaeoniflorin content could also work in combination with antioxidant enzymes for ROS removal. Waterlogging in the early stage also increased the content of paeoniflorins in the root of "Hongxiuqiu" in autumn. Albiflorin can enrich blood, ease spasmodic pain, and relieve depression [63]. When waterlogging was stopped, the albiflorin content increased in the root ("Taohuafeixue" > "Yangfeichuyu" > "Hongxiuqiu"), but decreased in the leaves. This change was positively correlated with flood resistance. In autumn, the content of albiflorin in roots showed a downward trend, indicating that the short-term waterlogging treatment had a negative impact on the content of albiflorin in roots, while the change in "Taohuafeixue" was not significant. According to the effect of waterlogging on the secondary metabolites in different parts of the tested plants, more aminoglycoside compounds, such as paeoniflorin, albiflorin and benzoylpaeoniflorin, can be obtained from the roots of herbaceous peony.

Studies have shown that gallic acid has pharmacological properties of scavenging free radicals, as well as antiinflammatory, antiviral, anticancer, and antioxidant effects [64]. The waterlogging treatment increased the production of gallic acid in the leaves of herbaceous peony ("Taohuafeixue" > "Yangfeichuyu" > "Hongxiuqiu"). The change in gallic acid content was positively correlated with waterlogging resistance in leaves. Waterlogging increased the flavonoid content in leaves of "Taohuafeixue" and "Yangfeichuyu" and in the roots of "Hongxiuqiu" Flavonoids play a role in scavenging free radicals, and their content increase with the antioxidant enzyme activity to scavenge ROS and protect plants against adversity [23]. Because of the content of phenolic acids and flavonoids in herbaceous peony roots tested were significantly lower than those in the leaves during the growth period, suggesting that they were mostly obtained in growing leaves.

\section{Conclusion}

This study explored the effects of short-term waterlogging on the physiological characteristics and secondary metabolite content of herbaceous peony. It was found that waterlogging could enhance the ability of this species to resist adversity by changing its microstructure, regulating its antioxidant system, and changing the content of secondary metabolites. These results suggest that herbaceous peony has certain water resistance and that waterlogging may not cause it fatal 
injury. Our results showed that the "Taohuafeixue" variety had the best waterlogging resistance. According to the effects of waterlogging on the content of active substances, suitable varieties of herbaceous peony were selected in order to obtain more secondary metabolites. During spring harvest, it is suggested to select "Yangfeichuyu" to get more paeoniflorin and albiflorin, and "Hongxiuqiu" to get benzoylpaeoniflorin. When plants were harvested in autumn after waterlogging in spring, select "Hongxiuqiu" to get more paeoniflorin and benzoylpaeoniflorin, and "Taohuafeixue" to get more albiflorin. In order to obtain more gallic acid and total flavonoids from leaves, waterlogging planting area can choose "Taohuafeixue" and "Yangfeichuyu". In the future, to provide a theoretical basis for the production and application of herbaceous peony, the time of waterlogging-induced damage should be prolonged and the range of varieties tested should be expanded. The limits of waterlogging tolerance can be further explored in different varieties, and the molecular mechanisms affecting the changes in pharmacological composition of herbaceous peony warrants investigation under waterlogging conditions.

\section{Acknowledgements}

The authors warmly thank Qingxia Zhang for their help during herbaceous peony sampling and other processes. This work was supported by the National Natural Science Foundation of China (31670663), Shandong Agricultural Engineering Forest Tree Breeding Project Corpus for High-grade Garden Flower Breeding (2130106).

\section{Conflicts of Interest}

The authors declare no conflicts of interest regarding the publication of this paper.

\section{References}

[1] Voesenek, B.S. (2008) Flooding Stress: Acclimations and Genetic Diversity. Annual Review of Plant Biology, 59, 313-339.

https://doi.org/10.1146/annurev.arplant.59.032607.092752

[2] Hirabayashi, Y., Mahendran, R., Koirala, S., Konoshima, L., Yamazaki, D., Watanabe, S., Kim, H., et al. (2013) Global Food Risk under Climate Change. Nature Climate Change, 3, 816-821. https://doi.org/10.1038/nclimate1911

[3] Chaves, M.M. and Oliveira, M.M. (2004) Mechanisms Underlying Plant Resilience to Water Deficits: Prospects for Water-Saving Agriculture. Journal of Experimental Botany, 55, 2365-2384. https://doi.org/10.1093/jxb/erh269

[4] Gao, Y.Y., Yu, T.H., Wu, J.G., Xue, A.H., Shi, P.L. and Huang, X.Y. (2018) Effects of Waterlogging Stress on Physicochemical Properties and Effective Components of Tobacco. Journal of Nanchang University (Natural Science), 42, 445-451.

[5] Deng, H.M., Long, C.Y., Cai, S.Z., Song, Y., Yan, R.X., Che, Y.R., Wang, C.J. and Xiao, Y. (2018) Morphology and Physiological Characteristics of Stachys lanata Seedling under Water Stress. Acta Botanica Boreali-Occidentalia Sinica, 38, 1099 1108 . 
[6] Mahdi, Y., Rieke, M., Robert, H., Sara, A. and Dirk, S. (2018) Impact of Drought and Salt Stress on the Biosynthesis of Alkaloids in Chelidonium majus L. Phytochemistry, 152, 204-212. https://doi.org/10.1016/j.phytochem.2018.05.007

[7] Barickman, T.C., Simpson, C.R. and Sams, C.E. (2019) Waterlogging Causes Early Modification in the Physiological Performance, Carotenoids, Chlorophylls, Proline, and Soluble Sugars of Cucumber Plants. Plants, 8, 160.

https://doi.org/10.3390/plants8060160

[8] Khan, M.A.M., Ulrichs, C. and Mewis, I. (2010) Influence of Water Stress on the Glucosinolate Profile of Brassica oleracea var. Italica and the Performance of Brevicoryne brassicae and Myzus persicae. Entomologia Experimentalis et Applicata, 137, 229-236. https://doi.org/10.1111/j.1570-7458.2010.01059.x

[9] Smirnoff, N. (1998) Plant Resistance to Environmental Stress. Current Opinion in Biotechnology, 9, 214-219. https://doi.org/10.1016/S0958-1669(98)80118-3

[10] Foyer, C.H., Descourvieres, P. and Kunert, K.J. (1994) Protection against Oxygen Radicals-An Important Defense Mechanism Studied in Transgenic Plants. Plant, Cell \& Environment, 17, 507-523. https://doi.org/10.1111/j.1365-3040.1994.tb00146.x

[11] Niyogi, K.K. (1999) Photoprotection Revisited: Genetic and Molecular Approaches. Annual Review of Plant Physiology and Plant Molecular Biology, 50, 333-359. https://doi.org/10.1146/annurev.arplant.50.1.333

[12] Cai, Q.S. (2014) Plant Physiology. Higher Education Press, Beijing.

[13] Li, X.B., Wang, W., Zhou, G.J., Li, Y., Xie, X.M. and Zhou, T.S. (2012) Production of Salvianolic Acid B in Roots of Salvia miltiorrhiza (Danshen) during the PostHarvest Drying Process. Molecules, 17, 2388-2407. https://doi.org/10.3390/molecules 17032388

[14] Si, C., Zhang, J.Y. and Xu, H.Z. (2014) Advances in Studies on Growth Metabolism and Response Mechanisms of Medicinal Plants under Drought Stress. China Journal of Chinese Materia Medica, 39, 2432-2437.

[15] Yan, X.F. (2001) Ecology of Plant Secondary Metabolism. Chinese Journal of Plant Ecology, 25, 369-340.

[16] Zhao, X.D. (2010) Application of Paeonia lactiflora in Gardens. Modern Agricultural Sciences and Technology, 17, 208-213.

[17] Cheng, M.L., Lu, C.P., Mo, N.J., Liu, L.Y. and Yi, Q. (2007) Research Progress of Paeonia lactiflora. Forest Inventory and Planning, 3, 44-49.

[18] Lin, F. (2011) Advances in Chemical Constituents and Characteristic Maps of Paeonia lactiflora. Chinese Journal of Hospital Pharmacy, 31, 1727-1730.

[19] Yu, X.N., Yuan, Q.L. and Hao, L.H. (2014) Historical Analysis of Herbaceous Peony as Symbol of Love in China. Journal of Beijing Forestry University (Social Sciences), 13, 26-31.

[20] Gao, Y., Li, H., Wang, S.W., Xie, Y.H., Yang, Q. and Zhang, B.L. (2014) Research Progress of Pharmacological Action and Pharmacokinetics of Gallic Acid. Northwest Pharmaceutical Journal, 29, 435-438.

[21] Shan, F.F. (2011) Separation, Purification and Antioxidant Activity on the Total Flavonoids from Leaves of Peony. Master's Thesis, Henan University of Science and Technology, Luoyang.

[22] Shen, M.L., Yan, B.J. and Qin, L.P. (2019) Research Progress on Different Geographical Areas, Processing Methods and Collecting Time of the Effective Compounds in Paeoniae Radix (Shaoyao). Journal of Zhejiang Chinese Medical Univer- 
sity, 43, 622-630.

[23] Gao, H.R., Wang, J.H., Guan, Y., Du, H.W. and Meng, X.C. (2019) Effect of High Temperature on Flavonoids of Glycyrrhiza uralensis. Journal of Chinese Medicinal Materials, 3, 525-530.

[24] Jiang, N.N., Wu, X.X., Wang, C.X., Sun, Y., Lu, J., Wang, W. and Fang, Y.F. (2017) A Review on the Annual Paeonia lactiflora Supply Technology. Forestry and Environmental Science, 33, 135-138.

[25] Tang, Y. (2018) The Effect of Storage and Sucrose Treatment on the Quality of the Cut Peony Flower. Qinghai University, Xining.

[26] Li, Z.L., Li, J. and Bai, F. (2019) Analysis on Key Techniques of Promoting Production and Cultivation of Cut Peony. Modern Rural Science and Technology, 4, 34+59.

[27] Wang, S.Z. (2018) Propagation and Cultivation Management Techniques of Paeonia lactiflora. Agriculture and Technology, 38, 127.

[28] Chang, Q.S., Zhang, L.X., Wang, J.Z., Wang, Z., Xu, S.J., Kang, L., Yan, J.Y., Yang, M.H., Zhao, Y.F. and Liu, Y. (2018) Effects of Drought Stress and Rewatering on Physiological Indexes of four Paeonia lactiflora Cultiva. Journal of Nanjing Foresty University Natural Science Edition, 42, 44-50.

[29] Wang, Q., Liu, J.X., Zhang, J.J. and Yu, X.X. (2014) The Effects of Growth and Physiology of Herbaceous Peony under Water Stress. Journal of Plant Genetic Resources, $15,1270-1277$

[30] Zhang, Y.Y., Zhang, S.J., Bian, T.T., Si, X.L., Niu, J.T., Xin, E.D., Wang, W.S. and Li, Y.F. (2019) New Progress in Pharmacological Action of paeoniflorin. Chinese Herbal Medicine, 50, 3735-3740.

[31] Miao, Y.P. and Yang, J. (2015) Research and Analysis on Chemical Constituents and Pharmacological Effect of Herbaceous Peony. World Latest Medicine Information, 15, 1-2.

[32] Chen, Y.H., Deng, L.X. and Ou, L.J. (2016) The Microstructure Changes of Different Pepper Species under Waterlogging. Hunan Agricultural Science, 3, 12-15.

[33] Cang, J. and Zhao, H.J. (2013) Experimental Course of Plant Physiology. Higher Education Press, Beijing, 85-153.

[34] Li, F.Y., Zang, X.D. and Cao, Y. (2017) Determination of Paeoniflorin of Cultivated Peony Root in Mudanjiang by HPLC. Northern Horticulture, 20, 149-153.

[35] Xu, L., Xia, G.H., Xu, L.M., Jiang, Y.P., Zhu, X.L., Wei, Y. and Wu, Q.H. (2017) Study on Optimization of Extraction Process of Total Favonoids from Oenanthe javanica and Its Content Determination. Anti-Infection Pharmacy, 14, 1654-1657.

[36] Garg, B.K., Kathju, S. and Burman, U. (2001) Influence of Water Stress on Water Relations, Photosynthetic Parameters and Nitrogen Metabolism of Moth Bean Genotypes. Biologia Plantarum, 44, 289-292. https://doi.org/10.1023/A:1010215812791

[37] Liu, D.H., Guo, L.P., Huang, L.Q., Jin, H., Wu, L.H., Zeng, Y., Zhang, H. and Yang, Y. (2011) Effects of Soil Water Content on Seedlings Growth and Active Ingredients of Salvia miltiorrhiza. China Journal of Chinese Materia Medica, 36, 321-325.

[38] Mckevlin, M.R., Hook, D.D. and Rozelle, A.A. (1998) A Daption of Plants to Flooding and Soilwaterlogging. In: Messina, M.G. and Conner, W.H., Eds., Southern Foresled Wellands. Ecology and Management, Lewis Publishers, 173-204.

[39] Zhao, K.F. (2003) Adaptation of Plants to Waterlogging Stress. Bulletin of Biology, 12, 11-14.

[40] Wang, Q. (2010) The Effect of Waterlogging on the Growth and Development of Maize in Seedling Stage and the Technical Measures for Disaster Reduction. China 
Seed Industry, 10, 86-87.

[41] Qu, G.M., Li, X.G., Zhao, F., Wang, H.X. and Shu, H.R. (1999) Effects of Water Stress on Microstructure of Leaves and Roots of Apple. Acta Horticulturae Sinica, 3, 9-11+13.

[42] Jiang, W., Cui, S.M., Li, H.X., Zhang, Y.T. and Bai, H.M. (2017) Effects of Salt Stress on Microstructure of Roots, Stems and Leaves of Pepper Seedlings. Vegetables, 3, 6-15.

[43] Wang, F.X., Xiao, K.Z., Jiang, S.F., Qu, M.Y., Lian, L., He, W., Chen, L.P., Xie, H.A. and Zhang, J.F. (2019) Mechanisms of Reactive Oxygen Species in Plants under Drought Stress. Chinese Science Bulletin, 64, 1765-1779.

https://doi.org/10.1360/N972018-01116

[44] Feroza, K.C., Rosa, M.R., Eduardo, B. and Ron, M. (2017) Reactive Oxygen Species, Abiotic Stress and Stress Combination. The Plant Journal, 90, 856-867. https://doi.org/10.1111/tpj.13299

[45] Zhang, Q. and Peng, Y.D. (2018) Physiological Response to Water Stress and Rewatering of Aesculus Chinensis Seedlings. Journal of Central South University of Forestry Science \& Technology, 38, 46-53.

[46] Qin, L., Ma, N., Wu, W.W., An, Y.Y., Xu, J.C., Qin, X.H. and Wang, J.X. (2015) Physiological Responses and Tolerance Evaluation of Fig Cultivars to Waterlogging. Acta Horticulturae Sinica, 42, 1273-1284.

[47] Wang, Z.W. (2018) The Effect of Growth Development and Composition Accumulation of Codonopsis pilosula under Different Soil Moisture. Master's Thesis, Zhejiang Sci-Tech University, Hangzhou.

[48] Zhang, Z., Wang, S.F., Xu, H.G. and Liu, M. (2009) The Effect of Low Temperature Stress on Tall Fescue Growth. Pratacultural Science, 26, 185-188.

[49] Luo, Q., Zhang, J.L., Hao, R.M., Xu, W.G., Pa,n W.M. and Jiao, Z.Y. (2007) Change of Some Physiological Indexes of Ten Tree Species under Waterlogging Stress and Comparison of Their Waterlogging Tolerance. Journal of Plant Resources and ENvironment, 1, 69-73.

[50] Men, Y., Wang, D., Li, B., Su, Y. and Chen, G. (2018) Effects of Drought Stress on the Antioxidant System, Osmolytes and Secondary Metabolites of Saposhnikovia divaricata Seedlings. Acta Physiologiae Plantarum, 40, Article No. 191. https://doi.org/10.1007/s11738-018-2762-0

[51] Huang, L.Q. and Guo, L.P. (2007) Secondary Metabolites Accumulating and Geoherbs Formation under Enviromental Stress. China Journal of Chinese Materia Medica, 32, 277-280.

[52] Maik, K., Jana, P., Elke, B., Ewald, S. and Dirk, S. (2015) Moderate Drought and Signal Transducer Induced Biosynthesis of Relevant Secondary Metabolites in Thyme (Thymus vulgaris), Greater Celandine (Chelidonium majus) and Parsley (Petroselinum crispum). Industrial Crops \& Products, 64, 158-166. https://doi.org/10.1016/j.indcrop.2014.10.062

[53] Babak, A.M., Elham, E. and Morteza, G. (2017) The Effect of Drought Stress on the Expression of Key Genes Involved in the Biosynthesis of Phenylpropanoids and Essential Oil Components in Basil (Ocimum basilicum L.). Phytochemistry, 139, 1-7. https://doi.org/10.1016/j.phytochem.2017.03.006

[54] Shao, X.W., Han, M., Han, Z.M., Kong, W.W. and Yang, L.M. (2006) Effects of Water Supply on Growth and Photosynthesis in Scutellaria baicalensis. Acta Ecologica Sinica, 26, 3214-3220.

[55] Liu, X.L. (2011) Study of Accumulate Mechanism and Drought Resistance of Phe- 
nolic Acids Under Drought in Salvia Miltiorrhiza Bunge. Northwest A\&F University, Yangling.

[56] Liu, Q., Zuo, Y.M., Yang, W.Z., Li, J.C., Xu, Z.L. and Zhang, J.Y. (2018) Effects of Rewatering after Water Stress on Growth and Accumulation of Saponins in Paris polyphylla Smith. Journal of Chinese Medicinal Materials, 41, 2277-2281.

[57] Liang, J.P., Jia, X.Y., Liu, Y.L., Wu, Y., Zhou, R. and Feng, Q.J. (2016) Effects of Drought Stress on Seedling Growth and Accumulation of Secondary Metabolites in the Roots of Astragalus membranaceus var. Mongholicus. Acta Ecologica Sinica, 36, 4415-4422. https://doi.org/10.5846/stxb201412162507

[58] Martin, L.C, Eric, P. and Cipollini, D.F. (2002) Effect of Nitrogen and Water Treatment on Leaf Chemistry in Horsenettle (Solanum carolinense), and Relationship to Herbivory by Flea Beetles (Epitrix spp.) and Tobacco Hornworm (Manduca sexta). Journal of Chemical Ecology, 28, 2377-2398.

https://doi.org/10.1023/A:1021494315786

[59] Heshmat, O., Hoda, S., Mehdi, S.S. and Tayebe, R. (2018) Balangu (Lallemantia sp.) Growth and Physiology under Field Drought Conditions Affecting Plant Medicinal Content. Plant Physiology and Biochemistry, 130, 641-646.

https://doi.org/10.1016/j.plaphy.2018.08.014

[60] Feng, W.K. and Guo, P. (2019) Advances in Pharmacological Effects of Paeoniflorin. Shandong Journal of Traditional Chinese Medicine, 38, 105-108.

[61] Gou, L.Q., Jiang, Y.Y., Wu, Y.C., She, Q.H., Hu, Q.Q., Yang, C. and Zhang, L. (2018) Advance in Studies on Effective Components and Pharmacological Activities of Paeonia lactiflora Pall. Genomics and Applied Biology, 37, 4022-4029.

[62] Sun, L.R., Cao, X., Hou, F.Q., Zhu, X.H. and Gao, T.M. (2008) Progressive Studies of Paeoniflorin. China Journal of Chinese Materia Medica, 33, 2028-2032.

[63] Wang, C.L. (2017) Study on Pharmacological Effects of Paeoniflorin and Albiflorin Based on the Efficacy of White Peony Nourishing and Softening Liver. Beijing University of Chinese Medicine, Beijing.

[64] Guo, X.Y., Yang, L., Yan, M.L., Hou, A.J., Man, W.J., Xing, X.D. and Cui, M.Y. (2018) Simultaneous Determination of Four Chemical Constituents in Paeonia lactiflora by HPLC. Journal of Hebei Traditional Chinese Medicine and, 33, 35-38. 